\title{
Los jóvenes y sus lecturas. ¿Deseable o cuestionable?
}

DOI: https://doi.org/10.32870/dse.v0i11.277

\section{María Alicia Peredo Merlo*}

Al reunir artículos relacionados con la lectura y la educación en un volumen de una revista educativa, parece obligado reflexionar sobre las fuertes críticas que se escuchan en diferentes espacios académicos y culturales, sobre todo para dar cuenta de dos grandes problemas: la escasa lectura que practican los mexicanos y el déficit de comprensión que se muestra en pruebas de comprensión lectora. Es común escuchar que México es un país de pocos lectores. La pregunta de si somos o no lectores es menos importante que preguntarnos qué importancia tiene leer, para quién es importante y qué beneficios obtiene una persona lectora. Esto nos obliga a clasificar los materiales y portadores textuales. Es indudable que hay ciclos de lectura, por ejemplo, un estudiante debe leer textos escolares y un profesional generalmente lee materiales relacionados con las actividades que realiza: un médico lee artículos científicos y un abogado leyes y códigos, entre otros. Un cocinero lee recetas de cocina y un desempleado puede buscar trabajo en el aviso de ocasión de un periódico. Sin embargo, hay un mito cultural que relaciona la lectura con el consumo de libros, revistas y periódicos, y un canon pedagógico que estipula qué se considera una buena lectura y cuál hay que desechar por inútil o perniciosa. Si juntamos ambos es de esperarse que una persona que ha salido de la educación básica o media superior sea un lector de literatura clásica e internacional y que utilice la lectura para conseguir mejores niveles de vida personal, de salud y sea capaza de ejercer sus derechos civiles. Desde luego cualquier tipo de lectura demanda comprensión, análisis y evaluación crítica; es decir, el lector es capaz de analizar y evaluar la calidad del texto. Parece que uniformáramos a los lectores competentes, pero la realidad nos hace evidente algunas otras consideraciones.

Por un lado, la diversidad de intereses por estratos sociales, disciplinares, de género y edad, de capital cultural, gustos y preferencias personales por una determinada temática o género literario, hacen que solamente podamos hablar de tendencias en los consumos. No obstante, las encuestas muestran datos interesantes que conviene analizar: por ejemplo, el escaso número de libros leídos por año y la casi nula asistencia a librerías. A pesar de ello, paradójicamente, los denominados li-

\footnotetext{
* Doctora en educación, profesora investigadora
} 
bros de autoayuda o de superación personal son un éxito editorial. Las ventas son altas y el número de reimpresiones da evidencia de su buena recepción; es decir, el mercado del libro nos conduce a pensar en un valor utilitario y de consumo.

La Cámara de la Industria Editorial Mexicana (CANIEM) clasifica en cuatro grandes categorías la producción editorial: libros de interés general (IG), libros científicos, técnicos y profesionales (CTP), libros de texto (LT) y libros religiosos (LR). Dentro de los libros de interés general (IG) se ubican los de psicología y filosofía. Los libros de superación personal son una subcategoría dentro de la subcategoría de psicología y filosofía.

El siguiente cuadro publicado previamente por Peredo (2012: 1-30), muestra tirajes globales de tres millones de ejemplares de este tipo de literatura popular. En promedio se escriben alrededor de 350 libros cada año, con un tiraje aproximado de 4000 libros por título. ${ }^{1}$ Desde luego que hay un aparato mercadológico atrás de estos datos pero indudablemente que dan cuenta de importantes ventas y por conclusión de consumo. Este tipo de literatura tiene estructuras lingüísticas muy sencillas, es de fácil comprensión y responde a los intereses de los jóvenes. Si bien es cuestionable que sea este tipo de materiales el que más llame su atención y que incluso sea recomendado por padres y profesores, esto pone en duda que se nos califique como un país de escasos lectores. Lo mismo sucede con las revistas poco científicas que tratan cuestiones amorosas, de moda y del glamur de la vida de los artistas, que también tienen altos tirajes además de que un ejemplar pasa por varios lectores. Por ejemplo, de la revista 15-20, dirigida a jóvenes, según la Dirección General de Medios de la Secretaría de Gobernación se venden 131506 ejemplares mensuales, lo que da cifras de 1518 072 ejemplares anuales, y si consideramos que éstos pasan por más de un lector, estamos hablando de millones de lectores. La revista TV Notas vende 624770 ejemplares semanales, lo que equivale a 32488040 revistas al año, cifra por demás impresionante. Y, por último Tú, revista quincenal para jóvenes, que vende 52348 cada dos semanas, lo que asciende a 5444192 revistas al año.

${ }^{<?>}$ Este dato se obtiene en la proporción del número de ejemplares y el número de nuevos títulos. 
Cuadro. Producción de libros de autoayuda

\begin{tabular}{|l|l|l|l|l|l|l|}
\hline Año & $\begin{array}{l}\text { Nuevos } \\
\text { títulos }\end{array}$ & Ejemplares & Reediciones & Ejemplares & Reimpresiones & Ejemplares \\
\hline 1999 & & & & & & \\
\hline 2000 & 358 & $1,492,809$ & 81 & 131,621 & 1,096 & $3,619,109$ \\
\hline 2001 & 263 & 807,471 & 8 & 16,523 & 773 & $1,707,238$ \\
\hline 2002 & 317 & $1,474,976$ & 15 & 57,906 & 677 & $1,705,533$ \\
\hline 2003 & 285 & $1,447,066$ & 16 & 23,196 & 656 & $1,568,755$ \\
\hline 2004 & 374 & $1,268,405$ & 46 & 132,583 & 551 & $1,806,157$ \\
\hline 2005 & 439 & $1,795,634$ & 69 & 123,190 & 916 & $1,991,890$ \\
\hline 2006 & 346 & $1,486,415$ & 29 & 99,144 & 929 & $2,864,453$ \\
\hline 2007 & 295 & $2,249,707$ & 15 & 90,953 & 588 & $2,969,170$ \\
\hline 2008 & 374 & $1,747,345$ & 33 & 93,159 & 702 & $2,038,080$ \\
\hline 2009 & 338 & $1,639,160$ & 48 & 89,696 & 582 & $1,808,356$ \\
\hline
\end{tabular}

Fuente: Datos construidos por Peredo y tomados de la CANIEM en sus publicaciones hasta el año 2009, fecha de la última a la que tuvimos acceso.

Conviene reflexionar si los jóvenes gustan de esta lectura porque es la que más se publicita. Si la respuesta fuera afirmativa, deberíamos pensar que, como dice Kalman (2003), el acceso y disponibilidad son dos factores que enmarcan las prácticas alfabéticas. Estos chicos tienen en su entorno cotidiano este tipo de materiales impresos y al preferirlos configuran un tipo de práctica lectora. Pero la respuesta es más compleja. Poulain habla de la mutación del modelo de práctica lectora o consumo cultural y afirma que no debemos lamentarnos, porque "los jóvenes sí leen, pero de otra manera, sin reverenciar a los grandes autores, ni confundirlos... la lectura de libros ocupa un lugar modesto entre los entretenimientos de los adolescentes" (Poulain, 2004: 43). Lo que está en juego es algo más que el consumo, debemos reflexionar si los jóvenes comprenden, gustan y se apropian de esta literatura, entonces ¿qué hace la escuela para alejarlos del gusto de leer?

Quizá convendría proponer literatura escrita para los intereses juveniles que responda a mejores estructuras literarias que conduzcan a los lectores al hábito y al placer de entrar a los mundos imaginarios que satisfacen ilusiones y fantasías propios de cada etapa en la vida.

\section{Referencias}

Kalman, J. (2003). "El acceso a la cultura escrita: la participación social y la apropiación de conocimientos en eventos cotidianos de lectura y escritura". Revista Mexicana de Investigación Educativa. México, núm. 17, vol. 8, pp. 37-66.

Peredo, M. A. (2012). "La cultura de la autoayuda impresa". Intersticios Sociales, El Colegio de Jalisco, Vol. 1, núm. 4, ISSN 2007-4964, pp. 1-30 
Poulaine, M. (2004). "Entre preocupaciones sociales e investigación científica: el desarrollo de sociologías de la lectura en Francia". B. Lahire. Sociología de la lectura. Barcelona: Gedisa, pp. 17-58. 